\title{
Pilot study investigating the utility of a specialized online symptom management program for individuals with myalgic encephalomyelitis/ chronic fatigue syndrome as compared to an online meditation program
}

This article was published in the following Dove Press journal:

Psychology Research and Behavior Management

2 September 2014

Number of times this article has been viewed

\section{Megan A Arroll \\ Elizabeth A Attree \\ Clare L Marshall \\ Christine P Dancey}

Chronic Illness Research Team, School of Psychology, University of East London, London, UK
Correspondence: Megan A Arroll Chronic Illness Research Team, School of Psychology, University of East London, Stratford Campus, Water Lane, London EI 5 4LZ, UK Email m.a.arroll@uel.ac.uk
Background: Myalgic encephalomyelitis/chronic fatigue syndrome (ME/CFS) is a long-term, debilitating condition that impacts numerous areas of individuals' lives. The two predominant treatment options for ME/CFS are cognitive behavioral therapy and graded exercise therapy; however, many people have found these techniques unacceptable or even damaging. This pilot study aimed to evaluate the utility of a specialized online symptom management program for $\mathrm{ME} / \mathrm{CFS}$ in comparison to an online meditation program in an effort to ascertain whether this tool could be a further option for those with ME/CFS.

Methods: This experimental design consisted of two interventions: a specialized online symptoms management program $(\mathrm{N}=19)$ and a control intervention based on an online meditation website $(\mathrm{N}=9)$. A battery of questionnaires, including measures of multidimensional fatigue, illness-specific symptoms, perceived control, and mindful awareness, were completed before the participants commenced use of the programs and following 8 weeks' use.

Results: Significant differences were found in the areas of chance and powerful others' locus of control, and sleeping difficulties, but not in ME/CFS symptomatology overall.

Conclusion: The specialized online program described in this study warrants further investigation, as it appears to influence perceived control and key ME/CFS symptoms over time.

Keywords: ME/CFS, perceived control, sleep, outcomes, online intervention

Myalgic encephalomyelitis/chronic fatigue syndrome (ME/CFS) is a condition characterized by severe and often debilitating fatigue, postexertional malaise, sleep disturbance, and autonomic, neuroendocrine, and immune manifestations. ${ }^{1}$ Epidemiological studies have produced varying rates of prevalence of this disorder from 3 to 2,800 per $100,000,{ }^{2-8}$ which is perhaps reflective of the difficulties in defining ME/CFS. Indeed, in one epidemiological study, rates varied from $0.03 \%-0.19 \%$ when using different diagnostic case criteria. ${ }^{8}$ Variation also exists in terms of whether ME/CFS has been self-reported or clinically assessed; a recent meta-analysis calculated pooled prevalence rates of $3.28 \%$ and $0.76 \%$, respectively. ${ }^{9}$ However, what is apparent is that this condition, whether self-identified or diagnosed objectively, is highly intrusive into individuals' lives, often disrupting work, interpersonal relationships, and previously enjoyed recreational activities. ${ }^{10}$ In addition, ME/CFS has a substantial impact on the wider economy; the average cost in treatments, lost income, and benefit payments was found 
to be $£ 3,515$ per individual with ME/CFS over a 3-month period. ${ }^{11}$ Therefore, there appears to be a clear rationale for finding effective, long-term treatments for ME/CFS.

In the UK, current guidelines from the National Institute for Health and Care Excellence suggest that cognitive behavioral therapy (CBT) and graded exercise therapy (GET) should be offered to those with ME/CFS. ${ }^{12}$ These suggestions are based on a body of evidence that shows CBT and GET to be effective treatment options. ${ }^{13-15}$ However, these studies included only the mildly and moderately affected, not houseand bed-bound individuals, and often had high drop-out rates; hence, how far this data can be generalized is questionable. The recent PACE trial in the UK, which compared CBT and GET to standard medical care and adaptive pacing therapy (APT), found the former techniques to be more effective. ${ }^{15}$ Twenty-two percent of those in the CBT arm of the trial, 22\% within the GET group, $8 \%$ who received APT, and $7 \%$ who engaged in standard medical care only were reported to have recovered following this multicenter trial. ${ }^{16}$

However, recent surveys by two of the largest charities in the UK, the ME Association and Action for ME, found a rather different picture to that of the aforementioned studies. Regarding GET, in a survey of 906 respondents, $33.1 \%$ said that they were "much worse" after the treatment, $23.4 \%$ said they felt slightly worse, $21.4 \%$ reported no change in symptoms, $18.7 \%$ stated that they improved, and $3.4 \%$ felt they had improved greatly. ${ }^{17}$ Similarly, Action for ME found that $22.2 \%$ of participants felt they had improved following GET, although $60.2 \%$ of respondents in the survey said it had made their condition worse, of which $44.1 \%$ reported much or very much worse symptomatology. ${ }^{18}$ These data should of course be viewed with caution, as these surveys could contain bias, but these results are useful in gaining an understanding of why some participants may have dropped out of GET trials, as it can be difficult to gauge this in randomized controlled trials (RCTs) if harms are not documented. ${ }^{19}$

In the face of unacceptable treatment options, many people turn to complementary and alternative medicine (CAM). In a study of comparable CAM use in twin pairs discordant for ME/CFS, $91 \%$ of those with the condition had engaged in a CAM technique, whereas $71 \%$ of the non-ME/CFS twins had used CAM in their lifetime. ${ }^{20}$ Eighty-one percent of the twins with ME/CFS found these therapies helpful. In a systematic review of CAM techniques used in the treatment and management of ME/CFS, ${ }^{21}$ it was found that in 60 of the 70 studies reviewed, $86 \%$ reported at least one positive effect (treatments ranged from supplementation to meditative practices). Fifty-two studies also found improvement in illness-related symptoms (74\%). ${ }^{21}$ In a slightly more recent review of 26 RCTs, evidence was found for the effectiveness of these various approaches in ME/CFS symptom alleviation. ${ }^{22}$ Hence, the literature that suggests nonorthodox perspectives could be useful for the management of ME/CFS.

Online therapy has become increasingly popular for a range of conditions, including anxiety and depression, ${ }^{23-25}$ panic disorder, ${ }^{26-28}$ post-traumatic stress disorder, ${ }^{29}$ addictions, ${ }^{30}$ irritable bowel syndrome, ${ }^{31}$ and other conditions such as stress, insomnia, and eating disorders. ${ }^{32}$ In terms of ME/CFS, a recent RCT of 135 adolescents with the condition made comparisons between an internet-based therapeutic program and usual care. ${ }^{33}$ Significant differences were found on measures of school attendance, fatigue, and overall functioning at 6 months, with those participants who engaged in the online program achieving better outcomes. Hence, there appears to be promise in the utility of newly developed, tailored online programs for ME/CFS.

This pilot study aimed to evaluate the utility of an online symptom management program that has been specifically designed for people with ME/CFS. This program is part of an integrated medicine approach to the treatment of ME/CFS, ${ }^{34}$ which has recently been investigated in terms of general health outcomes, multidimensional fatigue measures, ME/ CFS-specific symptoms, and perceived control. ${ }^{35}$ The results of this study showed promise, as participants improved statistically significantly from baseline to 3-month follow-up in fatigue, functional ability, and ME/CFS symptomatology. However, as the participants in this preliminary prospective study had additional psychological, nutritional, or combined support, it was not possible to elucidate the contribution of the online symptom management program on its own. Therefore, this study compared the ME/CFS online symptoms management program to online meditation guidance by examining self-reports of multidimensional fatigue, illness-specific symptoms, and perceived control at baseline and 8-week follow-up. An evaluation of mindful awareness was also included, as the control intervention was based on meditation principles.

Perceived control has been shown to be an important factor in ME/CFS. In Vercoulen et al's empirical model of the behavioral, cognitive, and affective factors involved in this condition, perceived control had a direct causal effect on fatigue. ${ }^{36}$ In prospective work, internal locus of control has been found to be negatively correlated with standardized functional impairment, but not fatigue severity or change scores, in those with ME/CFS. ${ }^{37}$ However, the remaining dimensions of locus of control (chance and powerful others) were not associated with outcomes. Hence, individuals with 
ME/CFS who had a sense that they could control their illness and symptomatology had less overall impairment (work, home management, social and leisure activities) 1 year from initial assessment. ${ }^{37}$ However, other studies have shown that participants who believed that the control of their condition was the responsibility of others, particularly doctors, had poorer psychological adjustment. ${ }^{38}$

Therefore, it was hypothesized that:

1. The experimental intervention will significantly decrease fatigue and illness-specific symptoms in comparison to the control intervention;

2. The experimental intervention will significantly increase internal locus of control and decrease beliefs in chance and powerful others in comparison to the control intervention;

3. Both the experimental and control conditions will increase mindful awareness.

\section{Methods}

\section{Study design and ethics}

The study was a between-participants experimental design, with participants allocated to an experimental or control intervention. Both interventions were online support programs, one designed specifically for $\mathrm{ME} / \mathrm{CFS}$ and one generic meditation site. Participants completed a battery of measures before commencing use of the online programs and 8 weeks later in order to gauge intervention effects.

\section{Experimental intervention}

The Optimum Health Clinic Foundation (OHCF; registered charity number 1131664) is a charity that offers psychological and nutritional therapies for people with $\mathrm{ME} /$ CFS. The founder and CEO of this clinic, with assistance from the team at $\mathrm{OHCF}$, developed an online symptom management program known as "Secrets to Recovery". The program was created based on the team's personal experience of ME/CFS, extensive work with individuals with this condition, and personal research efforts by the CEO. This tool is privately owned by Alex Howard and Associates Ltd and licensed to the charity per client. This program is formatted so that the user is able to focus on a variety of self-help areas in their everyday lives. It aims to help and alleviate a number of physical and psychological symptoms by using a combination of clinician advice, ME/ CFS patient success stories for support and encouragement, and taught activities which can be performed at home. The program is not rigid; users can spend long or short time spans on whichever areas they choose. But there is a slight level of order and structure, as the program is set into 15 main modules:

- Module 1: Coaching Yourself for Recovery

- Module 2: Psychology Essentials

- Module 3: Nutrition Essentials

- Module 4: Meditation Essentials

- Module 5: Emotional Freedom Technique (EFT) Essentials

- Module 6: Nutrition - Basic Supplements

- Module 7: Meditation and Breathing

- Module 8: Working with your Emotions

- Module 9: Advanced EFT

- Module 10: Pacing and Preventing Relapse

- Module 11: Nutrition - Healthy Cooking Basics

- Module 12: Conscious Transformation

- Module 13: EFT Sessions

- Module 14: Advanced Meditation Skills

- Module 15: Neuro-linguistic programming (NLP) Tools for Recovery (http://www.secretstorecovery.com/).

\section{Control intervention}

An online program that utilized a type of meditation in the form of a basic relaxation exercise was selected as a control intervention. This particular site was chosen as it also contains a number of phases or stages, and so is comparable to the experimental intervention. The control online program provides a plan for basic relaxation, divided into a five-step technique, which can be followed at home and gradually built upon. The five stages are as follows:

- Stage 1 is practicing deep breathing meditation for stress relief;

- Stage 2 is progressive muscle relaxation for stress relief;

- Stage 3 is a body scan meditation for stress relief;

- Stage 4 is mindfulness for stress relief;

- Stage 5 is visualization meditation for stress relief.

The instructions also contain useful advice for the best places and times of day to partake in basic relaxation (http://helpguide.org/mental/stress relief meditation yoga relaxation.htm).

\section{Ethics}

The study was granted ethical approval by the University of East London's Research Ethics Committee. Participants were informed in their "Invitation to Participate" that they maintained the right to withdraw from the study at any point during the process. All participants signed consent forms before embarking on the study, after reading about the study's purpose, aims, 
and objectives, and what would be required for participation. Participants were made aware that any data or correspondence received from them during any part of the study would remain confidential and would only be viewed by those researchers involved in the study. All data files were fully anonymized, with personal correspondence information kept in separate, password-protected files, or in locked cabinets if hard copies. At the end of the study, participants were debriefed and given the opportunity to ask any questions regarding the project. The participants were not deceived at any point during the study, and were able to participate from their own homes.

\section{Participants}

Participants were recruited though local ME/CFS support groups across the UK. Email addresses for support group leaders were sourced from the Action for ME website; leaders were then subsequently emailed relevant study information which was passed onto group members. Contact details were given for the research team so that potential participants could either ask questions about the study and/or register their interest in participating. For those who volunteered, further information and a consent form were either emailed or posted to the participant. Hence, informed consent was obtained when the participants signed the consent forms and posted them back to the research team.

In total, 30 individuals were recruited into the study; however, two participants $(6.66 \%)$ withdrew from the study due to deteriorating health and personal issues which prevented their use of the intervention. Both drop-outs had been assigned to the experimental group and were severely affected in terms of their Bell's CFS Disability Scale score. ${ }^{39}$ One was the oldest participant, recruited at 72 years of age with an illness duration of 19 years, scoring 10 on the Bell's Scale, which equates to the following description: "Severe symptoms at rest; bedridden the majority of the time. No travel outside of the house. Marked cognitive symptoms preventing concentration." The second participant to withdraw from the study was 31 years old, with an illness duration of 4 years, who scored 10 on the Bell's scale. This is a notable finding, as these were the only two participants in the study to score this severely on the disability scale. Both participants cited a sudden illness onset. It should be considered that these individuals told the research team that they found the process of completing the prequestionnaires quite arduous; therefore, thought should be given for future studies when recruiting the severely affected to ensure that the burden on this group is not overly high and also to find ways to make it possible for severely affected people to take part in research.
Inclusion criteria for this study were a self-reported diagnosis of ME/CFS and age of 18 years or more. Exclusion criteria included previous or current experience of the $\mathrm{OHCF}$ programs, although no one who volunteered for this study reported this.

\section{Materials}

The questionnaires chosen for this study were selected to encompass various areas of illness experiences in those with $\mathrm{ME} / \mathrm{CFS}$, including illness-specific symptoms, perceived control, different types of fatigue, and mindful awareness.

\section{Bell's CFS Disability Scale}

The Bell's CFS Disability Scale is used by doctors to assess the severity of ME/CFS symptomatology, the degree of activity impairment with both activity and rest, and functional ability regarding full-time work and daily tasks. ${ }^{39}$ The disability rating scale which has been developed is graded in boundaries of ten ranging from 100 (no symptoms at rest, no symptoms during exercise and a normal activity level) to 0 (severe symptoms, bedridden constantly, and unable to care for one's self). This measure was used at baseline only for characterization purposes.

\section{Multidimensional Health Locus of Control Scale}

Locus of control refers to individuals' beliefs regarding the extent to which they feel they are able to control or influence outcomes. The Multidimensional Health Locus of Control Scale (MHLC) focuses on whether individuals see control as either residing mainly in themselves, or elsewhere. ${ }^{40}$ The scale consists of 18 items over three subscales: "internal", "chance", and "powerful others", which has two dimensions, that of "doctors" and "other people". There are six items each for the internal and chance scales and three items for both powerful others scales, which are scored on a 6-point Likert scale from "strongly agree" to “strongly disagree". Cronbach's alpha coefficients range from 0.67 for powerful others to 0.77 for internal, which illustrates good internal reliability of the measure. In terms of convergent validity, the instrument correlates positively and significantly with associated scales from Levenson's locus of control measure ${ }^{41}$ from which the MHLC was based. ${ }^{40}$

\section{Multidimensional Fatigue Inventory}

The Multidimensional Fatigue Inventory (MFI) is a selfreport instrument consisting of 20 items devised to measure a broad spectrum of fatigue. ${ }^{42}$ It includes five distinct 
dimensions: general fatigue, physical fatigue, mental fatigue, reduced motivation, and reduced activity. The 5-point scale gives options ranging from "yes, that is true" to "no, that is not true" in response to items such as "I tire easily". Lower scores on this instrument reflect higher levels of fatigue. The internal consistency of the MFI is good, with average Cronbach's alpha coefficient of 0.84 across the five subscales. In a sample of radiotherapy patients, correlations between the subscales, and a visual analogue fatigue scale were 0.77 for general fatigue, 0.70 for physical fatigue, 0.61 for reduced activity, 0.56 for reduced motivation, and 0.23 for mental fatigue. ${ }^{42}$

\section{CDC CFS Symptom Inventory}

The Centers for Disease Control and Prevention (CDC) CFS Symptom Inventory ${ }^{43}$ is a self-report instrument that collects information about the presence, frequency, and intensity of 19 fatigue- and ME/CFS-related symptoms. The inventory includes eight ME/CFS defining symptoms as based on the CDC case definition: ${ }^{44}$ postexertional fatigue, unrefreshing sleep, problems remembering or concentrating, muscle pain, joint pain, sore throat, tender and swollen glands, and headaches. It also includes other accompanying symptoms on a six-point scale of perceived frequency $(0=$ absent, $5=$ all the time $)$ and severity $(0=$ none, $5=$ very severe $)$. Internal consistency is acceptable of this scale; the Cronbach's alpha coefficient equaling 0.88 . Regarding convergent validity, a correlation of 0.74 has been observed with the Chalder Fatigue Scale ${ }^{45}$ and -0.68 and -0.87 with the SF-36 $6^{46}$ "vitality" and "bodily pain" subscales, respectively. The CDC inventory has been shown to distinguish people with $\mathrm{ME} / \mathrm{CFS}$ from people with fatigue who were not diagnosed with the disorder. ${ }^{43}$

\section{Mindful Attention Awareness Scale}

The Mindful Attention Awareness Scale (MAAS) is a 15-item scale designed to assess a core characteristic of dispositional mindfulness, primarily, open or receptive awareness of and attention to what is taking place at the present. MAAS taps into a level of consciousness which is predictive of self-regulation and well-being constructs. ${ }^{47}$ The measure uses a 4-point Likert scale from "almost never" to "always", for items such as "It seems I am 'running on automatic' without much awareness of what I'm doing." In an evaluation of test-retest reliability, a correlation of 0.81 was found, demonstrating good temporal stability. The MAAS also correlates significantly with a number of well-being measures. ${ }^{47}$

\section{Procedure}

After informed consent was received from each participant, the questionnaire pack was either emailed or posted to the participants' homes. All participants were asked to initially complete the questionnaires before engaging in the online programs. Those within the experimental group were provided with usernames and passwords to access the symptom management program, whereas the control intervention was open-access. Participants were requested to partake in the programs for 8 weeks, and were advised to spend a minimum of 30 minutes each day for 5 days per week using the material. At the end of the 8-week intervention period, both the experimental and control group were asked to complete the questionnaire pack once again.

\section{Results}

A total of 28 participants completed the 8-week study, $25(89.3 \%)$ of whom were female and three (10.7\%) male. The mean age of participants was 44.43 (standard deviation $[\mathrm{SD}]=13.00$ ), and the age range was $20-68$ years. The mean illness duration (years) for all participants was 10.89 ( $\mathrm{SD}=8.05$; range $1-30$ years). Eleven (39.29\%) participants reported a sudden onset, while the remaining 17 (60.71\%) participants stated that their illness developed gradually.

The 28 participants were assigned to the experiment group (19 participants), or the control group (nine participants). There were no significant differences in the groups in terms of $\operatorname{sex}\left(X^{2}(1)=0.00, P>0.05\right)$. However, there was a significant difference in terms of age, with those in the control group being significantly older than participants in the experimental group $(t(26)=-2.45, P=0.021)$. There were no significant differences between the groups in fatigue symptomatology.

Descriptive statistics were calculated for each outcome variable by group (Table 1). Mean scores in all dimensions of fatigue were higher than both male and female norms for participants of similar age, ${ }^{48}$ although similar to radiotherapy patients. ${ }^{42}$ However, the participants in this sample reported less fatigue than previous samples of chronically fatigued patients. ${ }^{42}$ Therefore, it is possible that this sample consisted of individuals at the higher end of the functioning on the ME/CFS spectrum.

To evaluate within-group change from baseline to follow-up, a series of related $t$-tests were carried out (Table 2). Significant differences were found from baseline to follow-up in the experimental group in the mental fatigue dimension $(t(18)=3.33, P=0.004)$ and in reduced motivation $(t(18)=2.28, P=0.035)$. In terms of health locus of control, 
Table I Descriptive statistics for experimental and control groups at baseline and follow-up

\begin{tabular}{|c|c|c|c|c|c|c|c|c|}
\hline \multirow[t]{3}{*}{ Measures } & \multicolumn{4}{|c|}{ Baseline } & \multicolumn{4}{|c|}{ Follow-up } \\
\hline & \multicolumn{2}{|c|}{ Experimental } & \multicolumn{2}{|c|}{ Control } & \multicolumn{2}{|c|}{ Experimental } & \multicolumn{2}{|c|}{ Control } \\
\hline & Mean & SD & Mean & SD & Mean & SD & Mean & SD \\
\hline MFI general fatigue & 16.95 & 2.99 & 17.33 & 3.20 & 15.68 & 4.64 & I7.II & 2.62 \\
\hline MFI physical fatigue & 16.37 & 3.48 & 16.33 & 3.28 & 15.84 & 3.10 & 17.44 & 2.01 \\
\hline MFI mental fatigue & 14.05 & 3.37 & 14.78 & 4.71 & 12.11 & 3.75 & 14.33 & 5.66 \\
\hline MFI reduced activity & 14.47 & 3.73 & 16.89 & 4.08 & 14.47 & 8.44 & I7.II & 3.02 \\
\hline MFI reduced motivation & 11.63 & 4.25 & 12.67 & 3.54 & 9.63 & 2.99 & 12.22 & 3.11 \\
\hline MHLC internal & 0.45 & 0.20 & 0.56 & 0.27 & 0.64 & 0.13 & 0.52 & 0.18 \\
\hline MHLC chance & 0.47 & 0.18 & 0.44 & 0.19 & 0.35 & 0.10 & 0.48 & 0.13 \\
\hline MHLC doctors & 0.18 & 0.07 & 0.19 & 0.10 & 0.21 & 0.17 & 0.22 & 0.09 \\
\hline MHLC powerful others & 0.41 & 0.13 & 0.41 & 0.16 & 0.37 & 0.17 & 0.46 & 0.10 \\
\hline MHLC other people & 0.23 & 0.09 & 0.22 & 0.07 & 0.27 & 0.16 & 0.24 & 0.05 \\
\hline CDC total score & 148.00 & 70.81 & 142.00 & 75.66 & 130.42 & 76.00 & 137.63 & 63.47 \\
\hline CDC depression & 6.68 & 4.16 & 5.00 & 4.03 & 2.58 & 2.55 & 5.00 & 2.00 \\
\hline CDC sleeping problems & 12.74 & 8.39 & 12.11 & 10.64 & 9.16 & 6.25 & 11.89 & 10.04 \\
\hline CDC difficulty concentrating & 10.47 & 7.05 & 10.33 & 7.55 & 8.58 & 6.22 & 12.44 & 8.75 \\
\hline MAAS & 48.06 & 4.44 & 47.56 & 4.64 & 44.06 & 9.12 & 45.44 & 1.12 \\
\hline
\end{tabular}

Abbreviations: CDC, Centers for Disease Control Chronic Fatigue Syndrome Symptom Inventory; MAAS, Mindful Attention Awareness Scale; MFI, Multidimensional Fatigue Inventory; MHLC, Multidimensional Health Locus of Control Scale; SD, standard deviation.

Table 2 Results of outcome measures of baseline and follow-up

\begin{tabular}{|c|c|c|c|c|c|c|c|c|}
\hline \multirow[t]{2}{*}{ Measures } & \multirow[t]{2}{*}{ Groups } & \multirow[t]{2}{*}{ Mean difference } & \multirow[t]{2}{*}{$95 \% \mathrm{Cl}$} & \multicolumn{2}{|c|}{ Within-groups } & \multicolumn{2}{|c|}{ Between groups } & \multirow{2}{*}{$\begin{array}{l}\text { Effects } \\
\text { size }\end{array}$} \\
\hline & & & & $d f$ & $t$ & $d f$ & $F$ & \\
\hline MFI general & Experimental & 1.26 & $(-1.03$ to 3.56$)$ & 18 & 1.16 & I, 27 & 0.62 & 0.03 \\
\hline fatigue & Control & 0.22 & (-1.88 to 2.32$)$ & 8 & 0.24 & & & \\
\hline MFI physical & Experimental & 0.53 & (-1.03 to 2.09$)$ & 18 & 0.71 & I, 27 & 1.37 & 0.05 \\
\hline fatigue & Control & -1.11 & $(-3.01$ to 0.79$)$ & 8 & -1.35 & & & \\
\hline MFI mental & Experimental & 1.95 & $(0.72$ to 3.18$)$ & 18 & $3.33^{* *}$ & I, 27 & 0.79 & 0.03 \\
\hline fatigue & Control & 0.44 & $(-2.56$ to 3.45$)$ & 8 & 0.34 & & & \\
\hline MFI reduced & Experimental & 0.00 & $(-3.8 I$ to $3.8 I)$ & 18 & 0.00 & I, 27 & 0.06 & 0.00 \\
\hline activity & Control & -0.22 & $(-1.84$ to 1.40$)$ & 8 & -0.32 & & & \\
\hline MFI reduced & Experimental & 2.00 & (0.16 to 3.84$)$ & 18 & $2.28 *$ & I, 27 & 1.14 & 0.05 \\
\hline motivation & Control & 0.44 & $(-0.65$ to 1.54$)$ & 8 & 0.94 & & & \\
\hline \multirow{2}{*}{ MHLC internal } & Experimental & -0.18 & $(-0.30$ to -0.07$)$ & 18 & $-3.39 * *$ & I, 27 & 3.31 & 0.12 \\
\hline & Control & 0.04 & $(-0.11$ to 0.19$)$ & 8 & 0.63 & & & \\
\hline \multirow[t]{2}{*}{ MHLC chance } & Experimental & 0.12 & (0.03 to 0.22$)$ & 18 & $2.64 *$ & I, 27 & $8.96 * *$ & 0.27 \\
\hline & Control & -0.04 & $(-0.17$ to 0.10$)$ & 8 & -0.63 & & & \\
\hline \multirow[t]{2}{*}{ MHLC doctors } & Experimental & -0.03 & $(-0.12$ to 0.05$)$ & 18 & -0.075 & I, 27 & 0.01 & 0.00 \\
\hline & Control & -0.03 & $(-0.08$ to 0.03$)$ & 8 & -1.20 & & & \\
\hline MHLC powerful & Experimental & 0.04 & $(-0.04$ to 0.12$)$ & 18 & 0.99 & I, 27 & $4.42 *$ & 0.16 \\
\hline others & Control & -0.05 & $(-0.15$ to 0.05$)$ & 8 & -1.22 & & & \\
\hline MHLC other & Experimental & -0.04 & $(-0.12$ to 0.04$)$ & 18 & -0.95 & I, 27 & 0.03 & 0.00 \\
\hline people & Control & -0.03 & $(-0.08$ to 0.03$)$ & 8 & -0.97 & & & \\
\hline \multirow[t]{2}{*}{ CDC total score } & Experimental & 17.58 & $(-2.44$ to 37.59$)$ & 18 & 1.85 & I, 27 & 0.20 & 0.01 \\
\hline & Control & 4.38 & $(-26.88$ to 35.63$)$ & 8 & 0.33 & & & \\
\hline \multirow[t]{2}{*}{ CDC depression } & Experimental & 4.11 & ( 1.76 to 6.44$)$ & 18 & $3.68 * *$ & I, 27 & 4.08 & 0.15 \\
\hline & Control & 0.00 & $(-3.12$ to 3.12$)$ & 8 & 0.00 & & & \\
\hline CDC sleeping & Experimental & 3.58 & $(1.10$ to 3.04$)$ & 18 & $3.04 * *$ & I, 27 & $4.99 *$ & 0.17 \\
\hline problems & Control & 0.22 & $(-1.53$ tol.97) & 8 & 0.29 & & & \\
\hline CDC difficulty & Experimental & 1.89 & $(-0.35$ to 1.78$)$ & 18 & 1.76 & I, 27 & 3.00 & 0.11 \\
\hline concentrating & Control & -2.11 & (-6.96 to 2.74$)$ & 8 & -1.00 & & & \\
\hline \multirow[t]{2}{*}{ MAAS } & Experimental & 4.00 & $(-0.47$ to 1.89$)$ & 18 & 1.89 & I, 27 & 0.03 & 0.00 \\
\hline & Control & 2.11 & $(-1 . I I$ to 5.34$)$ & 8 & 1.51 & & & \\
\hline
\end{tabular}

Notes: Means difference, $95 \% \mathrm{Cl}$, paired $t$-test, ANCOVA, and between-groups effect sizes. $* P<0.05 ; * * P<0.01$.

Abbreviations: ANCOVA, analysis of covariance; CDC, Centers for Disease Control Chronic Fatigue Syndrome Symptom Inventory; Cl, confidence interval; MAAS, Mindful Attention Awareness Scale; MFI, Multidimensional Fatigue Inventory; MHLC, Multidimensional Health Locus of Control Scale. 
there were significant differences from time 1 to time 2 within the internal subscale $(t(18)=-3.39, P=0.003)$ and chance $(t(18)=2.64, P=0.017)$, in the expected directions. There were also differences over time in the experimental group in the depression item of the CDC CFS Symptom Inventory $(t(18)=3.68, P=0.002)$ and the sleeping problems item $(t(18)=3.04, P=0.007)$, but not in the overall score. There were no significant differences in any outcome measures from time 1 to time 2 in the control group (Table 2).

To investigate between-group differences, scores were analyzed using analysis of covariance so that baseline variation in scores and age could be controlled for (the former due to the small sample size and unequal group numbers and the latter as the two groups differed significantly on this variable). With these covariates entered into the analysis, there were no significant differences in terms of multidimensional fatigue. Significant differences were found in chance $(F(1,27)=8.96$, $P=0.006)$ and powerful others $(F(1,27)=4.42, P=0.046)$ perceived control. In the CDC CFS Symptom Inventory, a significant difference was found in the item sleeping problems $(F(1,27)=4.99, P=0.035)$ and depression scores approached significance $(F(1,27)=4.08, P=0.055)$. The largest effect size was observed in chance locus of control, although this was small at 0.27 .

\section{Discussion}

This pilot study aimed to investigate the utility of a specialized online symptom management program as compared to an online meditation program. While controlling for baseline measurements and age, significant differences were found between the groups in chance and powerful others locus of control and sleeping problems scores. Differences in depression across the groups approached significance. When looking at the groups independently over time, it was seen that change occurred in the experimental group only.

It is perhaps unsurprising that group differences were found in the powerful others item of the perceived control scale, as "Secrets to Recovery" shows individuals how they can make changes to their lives themselves. Similarly, the changes in chance perceived control would appear in line with the aims and content of the program. These are promising findings, as it has been shown that perceived control impacts functional ability and psychological adjustment in those with $\mathrm{ME} / \mathrm{CFS}{ }^{38}$

Interesting, the only $\mathrm{ME} / \mathrm{CFS}$ specific symptom to improve across groups was sleeping problems. This certainly warrants further investigation, as recent studies have shown a range of different sleep disturbances in those with ME/CFS. ${ }^{49}$
If the present online symptom management program can indeed help to rectify sleep issues, this would certainly be of benefit to the patient population. However, further, objective research would need to be conducted to corroborate these findings and also to uncover the mechanisms of action. Although there was not a significant difference across groups in depression, mental fatigue, or internal locus of control or motivation, there were differences from time 1 to time 2 in the experimental group. As this group was younger than the control group, it may be worth investigating these items in greater depth and perhaps tailoring the program further on the basis of age. Of course, additional work needs to be carried out to assess why there should be differences in these variables; this could be another area of future research.

It is unclear why neither intervention produced changes in mindful awareness. Mindfulness is a progressive practice, so perhaps developing this skill requires more than an 8 -week period. It would be useful to track participant usage of online programs as a form of compliance in future so that this important factor can be accounted for.

$\mathrm{ME} / \mathrm{CFS}$ is a complex disorder which impacts on the individual, family and wider society; therefore, new and innovative techniques that are acceptable to people should be developed. Until we know the precise mechanisms of this illness, CAM approaches could hold potential for symptom alleviation, a finding that has been observed in recent reviews. ${ }^{21,22}$

As this was a pilot study, it does have limitations. The sample size was very small, participants were not randomly allocated to groups, and the groups were uneven in number; future work should rectify these issues. In addition, recruitment was via support groups and ME/CFS diagnosis was self-reported; both factors could have produced a bias in this study. Future work should aim to recruit from a range of sources, including GP practice and/or specialist ME/CFS centers, and diagnosis should be confirmed independently.

Furthermore, it would be useful to delineate which components of the specialized online management program were responsible for the present findings. There are numerous modules in this program, and it may be the case that some are more "active" than others. This could be investigated first with qualitative approaches exploring participants' experiences of using this tool. Alternatively, mixed methodologies could be used to compare some elements of the program with others; these studies could also contain a qualitative section to capture more in-depth data that may highlight differing experiences of the individual modules.

Although efforts were made to find a comparable online program to the specialized ME/CFS symptom management 
program, due to the length and breadth of the latter, this was difficult; future, larger-scale work should aim to either devise an equivalent program or possibly combine a number of online resources to create an analogous tool for comparison. Finally, a longer follow-up needs to take place to see if improvements are maintained.

\section{Disclosure}

At the time this data was collected MAA worked for the Optimum Health Clinic Foundation. The authors report no other conflicts of interest in this work.

\section{References}

1. Carruthers BM, Jain AK, de Meirleir KL, et al. Myalgic encephalomyelitis/ chronic fatigue syndrome: clinical working case definition, diagnostic and treatment protocols. J Chronic Fatigue Syndrome. 2003;11(1):2003, 7-115.

2. Taylor RR, Jason LA, Richman JA, Torres-Harding SR, King C, Song S. Epidemiology. In: Jason LA, Fennell PA, Taylor RR, editors. Handbook of Chronic Fatigue Syndrome. Hoboken, NJ: Wiley, 2003;3-25.

3. Lloyd AR, Hickie I, Boughton CR, Spencer O, Wakefield D. Prevalence of chronic fatigue syndrome in an Australian population. Med J Aust. 1990;153(9):522-528.

4. Wessely S, Chalder T, Hirsch S, Wallace P, Wright D. The prevalence and morbidity of chronic fatigue and chronic fatigue syndrome: a prospective primary care study. Am J Public Health. 1997;87(9):1449-1455.

5. Reyes M, Nisenbaum R, Hoaglin DC, et al. Prevalence and incidence of chronic fatigue syndrome in Wichita, Kansas. Arch Intern Med. 2003;163(13):1530-1536.

6. Steele L, Dobbins JG, Fukuda K, et al. The epidemiology of chronic fatigue in San Francisco. Am J Med. 1998;105(3A):83S-90S.

7. Joyce J, Hotopf M, Wessely S. The prognosis of chronic fatigue and chronic fatigue syndrome: a systematic review. QJM. 1997;90(3):223-233.

8. Nacul LC, Lacerda EM, Pheby D, et al. Prevalence of myalgic encephalomyelitis/chronic fatigue syndrome (ME/CFS) in three regions of England: a repeated cross-sectional study in primary care. BMC Med. 2011;9:91.

9. Johnston S, Brenu EW, Staines D, Marshall-Gradisnik S. The prevalence of chronic fatigue syndrome/myalgic encephalomyelitis: a metaanalysis. Clin Epidemiol. 2013;5:105-110.

10. Dancey CP, Friend J. Symptoms, impairment and illness intrusivenesstheir relationship with depression in women with CFS/ME. Psychol Health. 2008;23(8):983-999.

11. McCrone P, Darbishire L, Ridsdale L, Seed P. The economic cost of chronic fatigue and chronic fatigue syndrome in UK primary care. Psychol Med. 2003;33(2):253-261.

12. NICE. Chronic fatigue syndrome/myalgic encephalomyelitis (or encephalopathy): diagnosis and management of chronic fatigue syndrome/myalgic encephalomyelitis (or encephalopathy) in adults and children [webpage on the Internet]. 2007. Available from: http:// www.nice.org.uk/nicemedia/live/11824/36190/36190.pdf. Accessed November 24, 2012.

13. Edmonds M, McGuire H, Price J. Exercise therapy for chronic fatigue syndrome. Cochrane Database Sys Rev. 2004;(3):CD003200.

14. Price JR, Mitchell E, Tidy E, Hunot V. Cognitive behaviour therapy for chronic fatigue syndrome in adults. Cochrane Database Syst Rev. 2008;16(3):CD001027.

15. White PD, Goldsmith KA, Johnson AL, et al. Comparison of adaptive pacing therapy, cognitive behaviour therapy, graded exercise therapy, and specialist medical care for chronic fatigue syndrome (PACE): a randomised trial. Lancet. 2011;377(9768):823-836.
16. White PD, Goldsmith K, Johnson AL, Chalder T, Sharpe M. Recovery from chronic fatigue syndrome after treatments given in the PACE trial. Psychol Med. 2013;43(10):2227-2235.

17. The ME Association. Managing my ME: What people with ME/ CFS and their carers want from the UK's health and social services. Buckinghamshire, UK: The ME Association, 2010.

18. Action for ME. GET, GAT and exercise on prescription survey results. InterAction. 2011;75(3):11-13.

19. Kindlon T. Reporting of harms associated with graded exercise therapy and cognitive behavioural therapy in myalgic encephalomyelitis/chronic fatigue syndrome. Bull IACFS/ME. 2011;19(2):59-111.

20. Afari N, Eisenberg DM, Herrell R, et al. Use of alternative treatments by chronic fatigue syndrome discordant twins. Integr Med. 2000;2(2): 97-103.

21. Porter NS, Jason LA, Boulton A, Bothne N, Coleman B. Alternative medical interventions used in the treatment and management of myalgic encephalomyelitis/chronic fatigue syndrome and fibromyalgia. JAltern Complement Med. 2010;16(3):235-249.

22. Alraek T, Lee MS, Choi TY, Cao H, Liu J. Complementary and alternative medicine for patients with chronic fatigue syndrome: a systematic review. BMC Complement Altern Med. 2011;11:87.

23. Christensen H, Griffiths KM, Mackinnon AJ, Brittliffe K. Online randomized controlled trial of brief and full cognitive behaviour therapy for depression. Psychol Med. 2006;36(12):1737-1746.

24. Spek V, Cuijpers P, Nyklícek I, Riper H, Keyzer J, Pop V. Internet-based cognitive behaviour therapy for symptoms of depression and anxiety: a meta-analysis. Psychol Med. 2007;37(3):319-328.

25. Andrews G, Cuijpers P, Craske MG, McEvoy P, Titov N. Computer therapy for the anxiety and depressive disorders is effective, acceptable and practical health care: a meta-analysis. PLoS One. 2010;5(10):e13196.

26. Klein B, Richards JC. A brief internet-based treatment for panic disorder. Behavioural and Cognitive Psychotherapy. 2001;29(1):113-117.

27. Klein B, Richards JC, Austin DW. Efficacy of internet therapy for panic disorder. J Behav Ther Exp Psychiatry. 2006;37(3):213-238.

28. Kiropoulos LA, Klein B, Austin DW, et al. Is internet-based CBT for panic disorder and agoraphobia as effective as face-to-face CBT? J Anxiety Disord. 2008;22(8):1273-1284.

29. Klein B, Mitchell J, Gilson K, et al. A therapist-assisted Internetbased CBT intervention for posttraumatic stress disorder: preliminary results. Cogn Behav Ther. 2009;38(2):121-131.

30. Gainsbury S, Blaszczynski A. A systematic review of Internet-based therapy for the treatment of addictions. Clin Psychol Rev. 2011;31(3): 490-498.

31. Hunt MG, Moshier S, Milonova M. Brief cognitive-behavioral internet therapy for irritable bowel syndrome. Behav Res Ther. 2009;47(9): 797-802.

32. Griffiths KM, Christensen H. Review of randomised controlled trials of Internet interventions for mental disorders and related conditions. Clinical Psychologist. 2006;10(1):16-29.

33. Nijhof SL, Bleijenberg G, Uiterwaal CS, Kimpen JL, van de Putte EM. Effectiveness of internet-based cognitive behavioural treatment for adolescents with chronic fatigue syndrome (FITNET): a randomised controlled trial. Lancet. 2012;379(9824):1412-1418.

34. Howard A, Arroll M. The application of integral medicine in the treatment of myalgic encephalomyelitis/chronic fatigue syndrome. J Integral Theory and Practice. 2011;6:25-40.

35. Arroll MA, Howard A. A preliminary prospective study of nutritional, psychological and combined therapies for myalgic encephalomyelitis/ chronic fatigue syndrome (ME/CFS) in a private care setting. $B M J$ Open. 2012;2(6).

36. Vercoulen JH, Swanink CM, Galama JM, et al. The persistence of fatigue in chronic fatigue syndrome and multiple sclerosis: development of a model. J Psychosom Res. 1998;45(6):507-517.

37. Ray C, Jefferies S, Weir WR. Coping and other predictors of outcome in chronic fatigue syndrome: a 1-year follow-up. J Psychosom Res. 1997;43(4):405-415. 
38. White K, Lehman DR, Hemphill KJ, Mandel DR, Lehman AM. Causal attributions, perceived control and psychological adjustment: A study of chronic fatigue syndrome. J Appl Soc Psychol. 2006;36(1):75-99.

39. Bell DS. The doctor's guide to chronic fatigue syndrome: understanding, treating, and living with CFIDS. Cambridge, MA: Da Capo Press, 1995.

40. Wallston KA, Wallston BS, DeVellis R. Development of the Multidimensional Health Locus of Control (MHLC) Scales. Health Educ Monogr. 1978;6(2):160-170.

41. Levenson H. Multidimensional locus of control in psychiatric patients. J Consult Clin Psychol. 1973;41(3):397.

42. Smets EM, Garssen B, Bonke B, De Haes JC. The Multidimensional Fatigue Inventory (MFI) psychometric qualities of an instrument to assess fatigue. J Psychosom Res. 1995;39(3):315-325.

43. Wagner D, Nisenbaum R, Heim C, Jones JF, Unger ER, Reeves WC. Psychometric properties of the CDC Symptom Inventory for assessment of chronic fatigue syndrome. Popul Health Metr. 2005;3:8.

44. Fukuda K, Straus SE, Hickie I, Sharpe MC, Dobbins JG, Komaroff A. The chronic fatigue syndrome: a comprehensive approach to its definition and study. International Chronic Fatigue Syndrome Study Group. Ann Intern Med. 1994;121(12):953-959.
45. Chalder T, Bereloitz G, Pawlikowska T, et al. Development of a fatigue scale. J Psychosom Res. 1993;37(2):147-153.

46. Ware JE Jr, Sherbourne CD. The MOS 36-item short-form health survey (SF-36). I. Conceptual framework and item selection. Med Care. 1992;30(6):473-483.

47. Brown KW, Ryan RM. The benefits of being present: mindfulness and its role in psychological well-being. J Pers Soc Psychol. 2003;84(4): $822-848$.

48. Lin JM, Brimmer DJ, Maloney EM, Nyarko E, Belue R, Reeves WC. Further validation of the Multidimensional Fatigue Inventory in a US adult population sample. Popul Health Metr. 2009;7:18.

49. Gotts ZM, Deary V, Newton J, Van der Dussen D, De Roy P, Ellis JG. Are there sleep-specific phenotypes in patients with chronic fatigue syndrome? A cross-sectional polysomnography analysis. BMJ Open. $2013 ; 3(6)$.

\section{Publish your work in this journal}

Psychology Research and Behavior Management is an international, peerreviewed, open access journal focusing on the science of psychology and its application in behavior management to develop improved outcomes in the clinical, educational, sports and business arenas. Specific topics covered include: Neuroscience, memory \& decision making; Behavior

\section{Dovepress}

modification \& management; Clinical applications; Business \& sports performance management; Social and developmental studies; Animal studies. The manuscript management system is completely online and includes a quick and fair peer-review system. Visit http://www.dovepress. com/testimonials.php to read real quotes from published authors.

Submit your manuscript here: http://www.dovepress.com/psychology-research-and-behavior-management-journal 